\title{
Effect of Shakeout Time on Microstructure and Hardness Properties of Grey Cast Iron
}

\author{
Saliu Ojo Seidu, Daniel Toyin Oloruntoba, Iyiola Olatunji Otunniyi \\ Metallurgical and Materials Engineering, Federal University of Technology, Akure, Nigeria \\ Email: seidu2@yahoo.co.uk
}

Received 7 March 2014; revised 1 May 2014; accepted 17 May 2014

Copyright (C) 2014 by authors and Scientific Research Publishing Inc.

This work is licensed under the Creative Commons Attribution International License (CC BY). http://creativecommons.org/licenses/by/4.0/

c) (i) Open Access

\begin{abstract}
Solidification process of grey cast iron largely determines the resultant carbon precipitates in form of graphite or carbides. Microstructure and hardness properties of grey iron were therefore studied. Aggregate scraps were melted with varying inoculants composition of $0.1 \mathrm{wt} \%, 0.2 \mathrm{wt} \%$ and $0.3 \mathrm{wt} \%$. Cast produced was shaken out of the mould at various timing. Microstructures of the samples were determined and analyzed. Hardness properties were equally evaluated. It was observed that the occurrence of carbides was more with 0.25 hrs shakeout time than other varying timing. Increasing shakeout time was found to decrease hardness and increase the carbide grain size. When the ferrosilicon content increases, there is a gradual decrease in the hardness properties from 59.6 HRC to 53.2 HRC for 0.25 hrs shakeout time cast sample. Similar decreases were observed for various timing analyzed.
\end{abstract}

\section{Keywords}

Shakeout Time, Microstructure, Hardness, Inoculation, Undercooling

\section{Introduction}

Cast iron is an alloy that has been used extensively for so many years because of its price, excellent cast ability and good mechanical properties. The cast ability of the alloy is as a result of carbon precipitates as graphite during solidification. Due to the precipitate of carbon as graphite, there will be an expansion which counteracts the general shrinkage of the metal during solidification [1]. Solidification process by which a metal freezes in the mould plays a vital role in determining the properties of the as cast alloy. This is as a result of: the initial uniform composition in liquid becomes non-uniform as the liquid transform to solid; different solidification gives rise to different microstructures of the solid and also, some casting defects depend on the manner in which the alloy is solidified in a mould [2]. Therefore, solidification structure of any casting has the obvious influence on the final microstructure and properties.

How to cite this paper: Seidu, S.O., Oloruntoba, D.T. and Otunniyi, I.O. (2014) Effect of Shakeout Time on Microstructure and Hardness Properties of Grey Cast Iron. Journal of Minerals and Materials Characterization and Engineering, 2, $346-350$. http://dx.doi.org/10.4236/jmmce.2014.24039 
Increasing cooling rate increases the primary austenite quantity; this is as a result of decrease in eutectic temperature thus extending growing time of the austenite dendrite [3].

Inoculation is therefore a means of controlling the structure and properties of a grey cast iron by minimizing under cooling and increasing the nucleation site during solidification. Inoculants are materials that are added to liquid metal prior to casting in a bid to provide suitable phase for graphite nucleation before solidification takes place [4]. The basic purpose of adding inoculants to the melt is to provide adequate nucleation sites for carbon to precipitate as graphite rather than cementite. This addition, if it is adequately added will prevent undercooling down to temperature below the metastable eutectic temperature where carbidic structures are formed or reduce it if is otherwise added [5]. Graphitization affects solidification rate. The slower the rate, the greater the tendency for graphite to form. A moderate cooling rate forms a more pearlitic matrix, while a slow cooling rate forms a more ferritic matrix [6].

Shakeout time is a factor that affects the hardness of a material. It is very important as it determines the pearlite ferrite distribution and carbide formation. It was reported [7] that the longer the shakeout times the more the pearlite-ferrite distribution and fewer the carbide formations [8]. Reported that the shorter the shakeout time, the finer the grain size because there will not be enough time for the grain size to distribute themselves and this consequently makes the casting to be hard.

Shakeout time also has a significant influence on the grain size. The longer the shakeout time, the coarse the grain size and consequently the softer the casting. Also, the shorter the shakeout time, the finer the grain size as the grains will not have enough time to distribute themselves and consequently the harder the casting. Thus a reasonable shakeout time must be reached to meet up with a pearlite ferrite distribution and carbide formation. This research seeks to establish adequate ferroalloy quantity and to actually recommend possible shakeout time for a jobbing foundry works.

\section{Materials and Method}

Experimental heats were obtained from carefully selected and cleaned scraps to avoid melt contamination during melting. Scraps such as cast iron engine block, foundry returns, ferro-alloys and pure metals were melted in a 60 $\mathrm{kg}$ rotary furnace at the melting temp of cast iron which is $1300^{\circ} \mathrm{C}$. In other to ensure total melting of material charge, it was supper heated to $1550^{\circ} \mathrm{C}$ temperature before tapping. The quantity of melts required to cast the moulds were determined with relevant design calculations. During tapping of the resulting liquid metal from the furnace at the temperature of $1420^{\circ} \mathrm{C}, 0.1 \mathrm{wt} \%, 0.2 \mathrm{wt} \%$ and $0.3 \mathrm{wt} \%$ inoculant $(\mathrm{FeSi})$ which was believed to have important effect on the formation of graphite nuclei during solidification was added to the metal stream so as to allow uniform dissolution of the inoculant in the melt. Thereafter, the melt was quickly poured into prepared moulds to avoid fading of the inoculants after which cooling and solidification occurred. Five moulds were prepared and the casting was made, they were thereafter left to cool for 15 mins, 45 mins, 1 hour 30 mins, 5 hours and 10 hours respectively before shaking out.

\subsection{Metallography}

Specimens for microscopy studies were prepared from the scrap (automobile part) and cast samples by machining to dimensions of $10 \mathrm{~mm}$ length, $10 \mathrm{~mm}$ breadth and $8 \mathrm{~mm}$ thickness; they were mounted on thermosetting material known as Bakelite for convenient handling. Thereafter, the surfaces of the specimens were then flattened by filing and grinding using laboratory grinding and polishing machines with a set of emery papers of 120 , 240, 320, 400, 600, 1000 and 1200 microns [9]. The grinding was done in order of coarseness of the papers. As each specimen was change from one emery papers to the other, it was turned through an angle of $90^{\circ}$ so as to remove the scratches sustained from the previous grinding. After grinding, the specimens were polished using rotary polishing machine, to give it mirror like surface, and in conformity with the standard, a polishing cloth was used to polish the surface of the specimens [10]. The samples were etched using $2 \%$ nital solution before the microstructure examination was performed with optical microscope.

\subsection{Hardness Test}

Hardness test was carried out with the use of digital indentech Rockwell hardness tester with a maximum load of 159 kgf. The flat surface of the sample is put at the pointer of the machine. The sample is held together by tightening of the knob. As the grip on the sample increases, indications will be seen on the digital reader. At the fi- 
nal gripping, the machine gives a final sign, and the sample is left at the mouth. The machine displays the hardness value and it is recorded. The procedure is repeated five times for each sample, picking five different points on each sample.

\section{Results and Discussion}

\subsection{Chemical Composition}

The combined effect of carbon and silicon which could be studied under carbon equivalent was calculated. Table 1 and Figure 1 show the chemical composition and the effect of inoculant's addition on the carbon equivalent respectively. It is revealed that increase in ferrosilicon addition increases the carbon equivalent. The alloy with $0.3 \mathrm{wt} \%$ inoculants which appears to have high CE will have less tendency to shrinkage defect than alloy with low CE since alloy with lower CE solidifies over a long temperature range as compared to shorter temperature range of high $\mathrm{CE}$.

\subsection{Hardness Properties}

Table 2 shows that the hardness values decreased with increasing FeSi inoculant addition at different shakeout time. The hardness value for the un-inoculated iron is higher than the inoculated irons. This is due to the higher degree of undercooling which is usually associated with short shakeout time. The number of stable eutectic graphite nuclei that would be formed will be smallest at short shakeout time compare to long shakeout time; this is because of the large degree of undercooling which does not favour the nucleation of graphite cells. The hardness test result obtained for $0.1 \% \mathrm{FeSi}$ is the highest due to its high propensity to having more carbide in its structure.

As the quantity of FeSi inoculants' addition increased there is an appreciable progressive decrease in the hardness values; the reason for this is the increased graphite eutectic cells encourage by the inoculation. Invariably, the carbides would be less. This large amount of eutectic graphite causes the hardness of the metal matrix to

Table 1. Chemical analysis of the resulting alloy with their carbon equivalent.

\begin{tabular}{cccccccccccc}
\hline Element & $\mathrm{C}$ & $\mathrm{Si}$ & $\mathrm{Mn}$ & $\mathrm{P}$ & $\mathrm{S}$ & $\mathrm{Cr}$ & $\mathrm{Ni}$ & $\mathrm{Mo}$ & $\mathrm{Fe}$ & $\mathrm{C} . \mathrm{E}$ \\
\hline $0.0 \% \mathrm{FeSi}$ & 3.157 & 1.02 & 0.234 & 0.03 & 0.0801 & 0.090 & 0.003 & 0.002 & 94.90 & 3.507 \\
$0.1 \% \mathrm{FeSi}$ & 3.108 & 2.250 & 0.2229 & 0.0283 & 0.0703 & 0.123 & 0.096 & 0.021 & 93.82 & 3.867 \\
$0.2 \% \mathrm{FeSi}$ & 3.102 & 2.980 & 0.313 & 0.03 & 0.063 & 0.110 & 0.050 & 0.011 & 93.04 & 4.105 \\
$0.3 \% \mathrm{FeSi}$ & 3.100 & 3.300 & 0.209 & 0.038 & 0.040 & 0.094 & 0.061 & 0.025 & 92.13 & 4.212 \\
\hline
\end{tabular}

C.E: carbon equivalent.

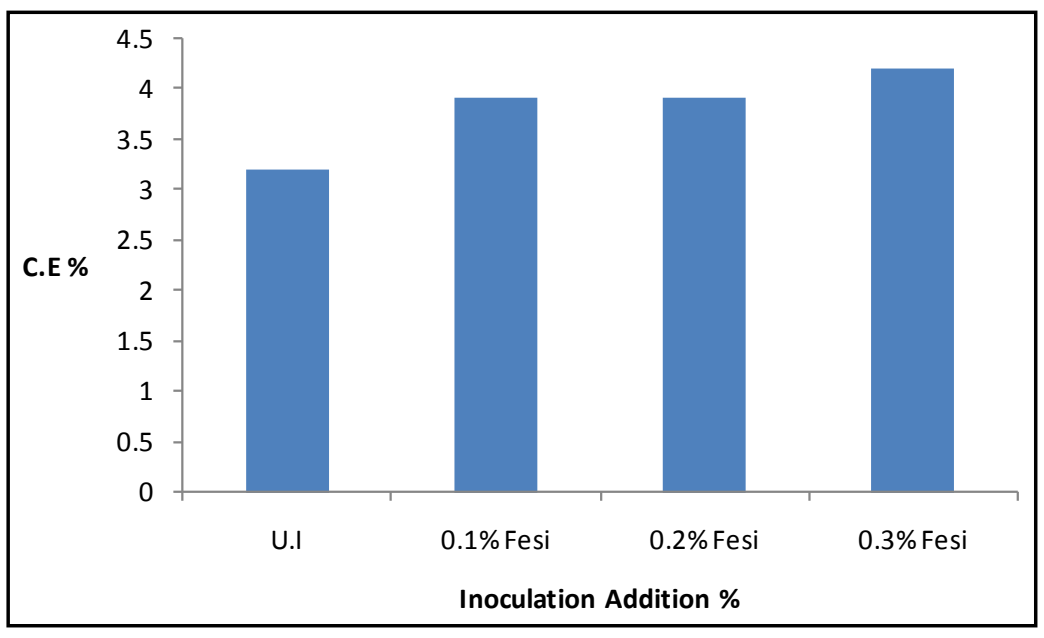

Figure 1. Influence of inoculant addition on the chemical equivalent. 
decrease. In general, grey cast iron, among the most widely used ferrous material for a given hardness is the most machineable, which is a function of the graphite flakes presence in the matrix.

\subsection{Micro-Structure Properties}

The graphitization phenomenon for various samples that was shaken out for 15 minutes shown in Figure 2 has inherent small graphite particles when compared with various shakeout time of 5 - 10 hrs. This effect was due

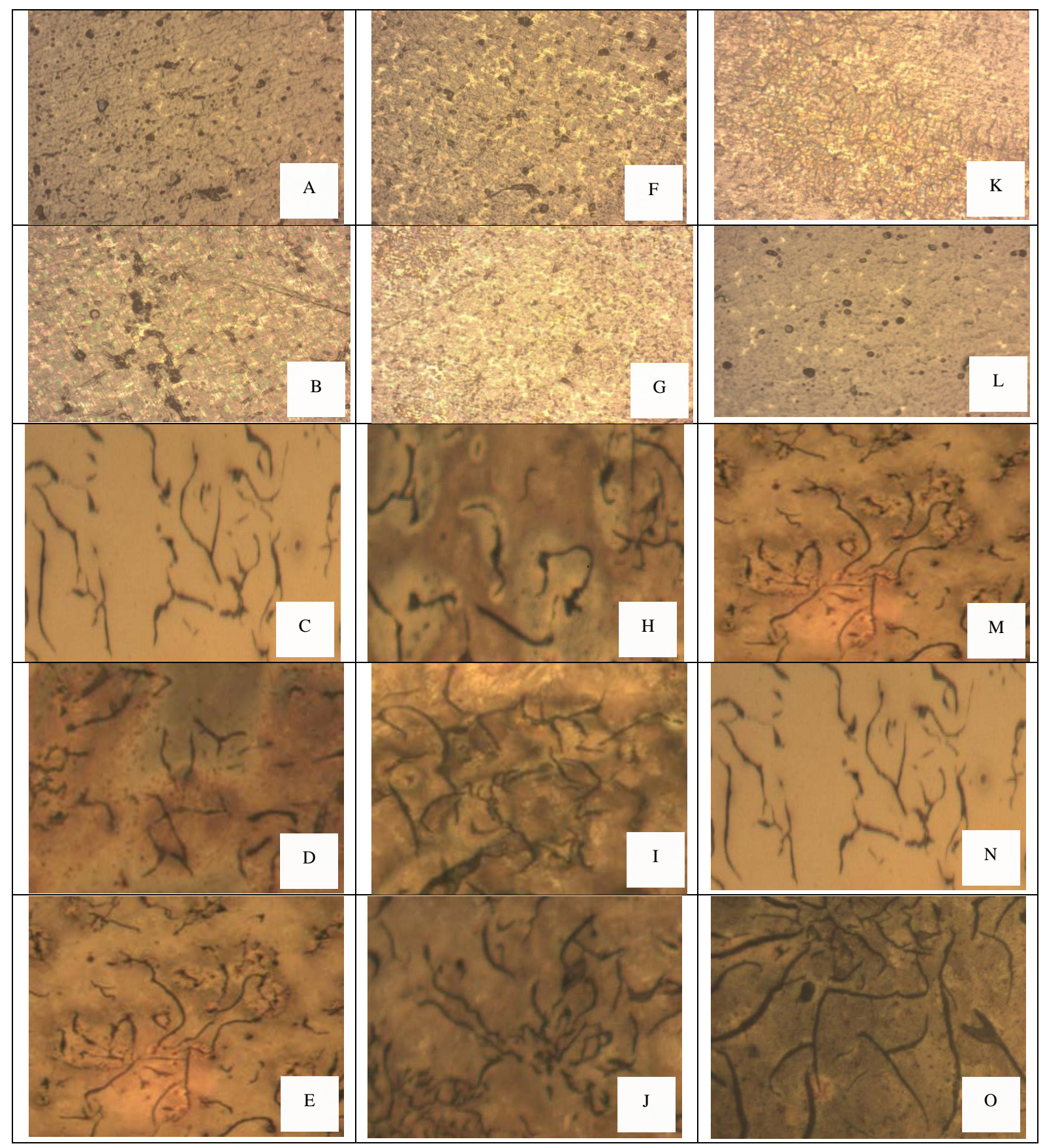

Figure 2. Optical micrographs of sample cast in sand mold. Pouring temperature $1400^{\circ} \mathrm{C} \times 100$; (A)-(E) Cast iron containing $0.1 \%$ FeSi. ((A) = 15 mins, (B) = 45 mins, $(C)=1 \mathrm{hr}$ and 30 mins, (D) = $5 \mathrm{hrs},(\mathrm{E})=10 \mathrm{hrs}) ;(\mathrm{F})-(\mathrm{J})$ Cast iron containing $0.2 \%$ FeSi. $((\mathrm{F})=15$ mins, $(\mathrm{G})=45 \mathrm{mins},(\mathrm{H})=1 \mathrm{hr}$ and $30 \mathrm{mins},(\mathrm{I})=5 \mathrm{hrs},(\mathrm{J})=10 \mathrm{hrs})$; $(\mathrm{K})-(\mathrm{O})$ Cast iron containing $0.3 \%$ FeSi. $((\mathrm{K})=15$ mins, $(\mathrm{L})=45$ mins, $(\mathrm{M})=1 \mathrm{hr}$ and 30 mins, $(\mathrm{N})=5 \mathrm{hrs},(\mathrm{O})=10 \mathrm{hrs})$. 
Table 2. Effect of shake-out time on hardness properties for varying inoculants composition.

\begin{tabular}{cccc}
\hline Shakeout time (hrs) & HRC (0.1 wt\%) & HRC (0.2 wt\%) & HRC (0.3 wt\%) \\
\hline 0.25 & 59.6 & 55.3 & 53.2 \\
0.75 & 58.7 & 54.2 & 52.1 \\
1.50 & 54.7 & 53.6 & 51.2 \\
5.00 & 52.9 & 52.1 & 50.5 \\
10.00 & 51.2 & 50.9 & 49.1 \\
\hline
\end{tabular}

to the degree of undercooling across each sample, which obviously would be most rapid in the short shakeout time due to the absence of inoculation or insufficient nuclei to aid the initiation of graphite during the course of solidification [11]. 0.1 wt\% Ferro-silicon inoculants addition produced more flakes in 5 - 10 hrs than in 15 minute across the samples. A well outline coarse graphite flakes occur at 5 - 10 hrs shakeout time while a fine graphite flake occur at 15 minute shakeout time for all the samples. This is because graphite nuclei nucleated and grow more at a relatively low cooling rate provided by FeSi inoculation in 5 - 10 hrs.

However, improved graphitization is achieved with increasing sequenced of inoculant addition until large dispersed graphite flakes across the matrix or the background metal when $0.3 \mathrm{wt} \% \mathrm{FeSi}$ was introduced into the ladle. This graphite flake morphology is correlative of type A graphite, resulted from good inoculating condition.

\section{Conclusions}

In this work, the effect of shakeout time on microstructures and hardness properties in grey cast iron was studied. The result shows that:

1) Silicon has a significant effect on the relative amount of graphite and cementite in the matrix. Silicon tends to make the cementite unstable such that it can decompose the graphite that is being produced. Hence more quantity of FeSi inoculant produces higher graphite flake distribution.

2) The hardness properties decreas as inoculants addition increased but it tends to be higher in short shakeout time as the number of stable eutectic graphite nuclei formed is lower.

\section{References}

[1] Kurz, W. and Fisher, D.J. (1986) Solidification of Single-Phase Alloys, Principle of Solidification. Trans Tech Publications Ltd., 121.

[2] Beno, J. and Jelinek, P. (2009) Solution of Negative Impact of Carbonaceous Additive to Bentonite Mixtures. International PhD Foundry Conference.

[3] Tonkovic, M.P., Jovoz, V. and Igorz, M. (2009) The Effect of Inoculants on Hardness and Machinability of Grey Cast Iron with Flake Graphite. Materials and Geoenvironment, 58, 521-530.

[4] Elkem, A.S. (2009) Cast Iron Inoculation-The Technology of Graphite Shape Control. Foundry Products Division, Oslo.

[5] Ojo, S.O. and Riposan, I. (2012) Alloy Selection for in Mould Inoculation to Control Chill Width in Ductile Iron Institute of Materials, Minerals and Mining. Material Science and Technology, 28, 576-581. http://dx.doi.org/10.1179/1743284711Y.0000000117

[6] Seidu, S.O. and Ogunniyi, I.O. (2013) Control of Chilling Tendency in Grey Cast Iron Reuse. Materials Research, 16, 145-149. http://dx.doi.org/10.1590/S1516-14392012005000160

[7] Jain, P.L. (1997) Principles of Foundry Technology. Tata McGraw-Hill, India.

[8] Flin, R. (1963) Fundamentals of Metal Casting. Addison-Lee, New York.

[9] Kehl, G.L. (1949) The Principles of Metallographic Laboratory Practice.

[10] Hughes, K.V. (1994) Practical Microscopical Metallography. University of Missouri Extension, Columbia Publication.

[11] Krause, D.E. (1969) Grey Iron-A Unique Engineering Material. ASTM Special Technical Publication, Philadelphia, 3-28. 
Scientific Research Publishing (SCIRP) is one of the largest Open Access journal publishers. It is currently publishing more than 200 open access, online, peer-reviewed journals covering a wide range of academic disciplines. SCIRP serves the worldwide academic communities and contributes to the progress and application of science with its publication.

Other selected journals from SCIRP are listed as below. Submit your manuscript to us via either submit@scirp.org or Online Submission Portal.
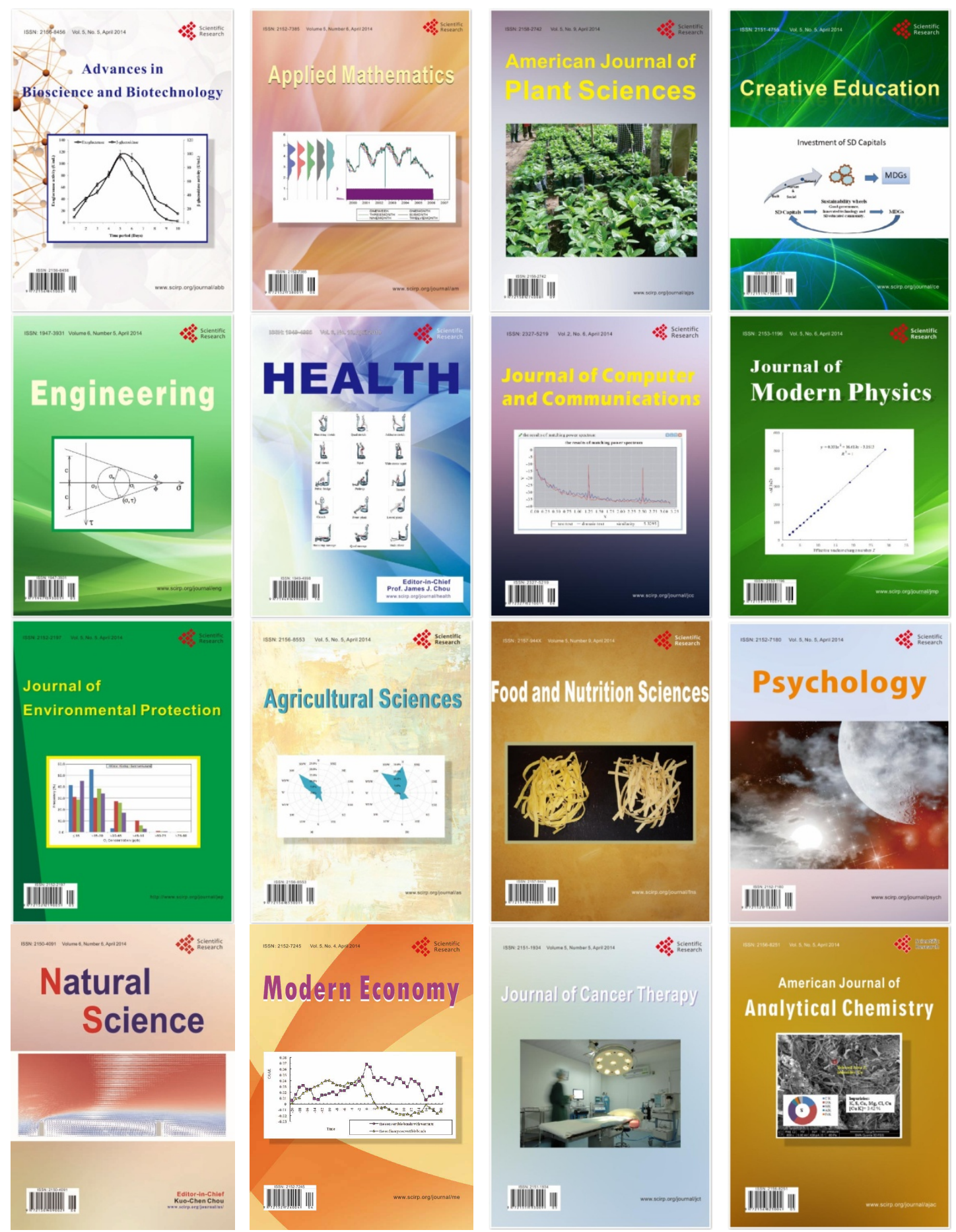